\title{
Retinal ganglion cell degeneration correlates with hippocampal spine loss in experimental Alzheimer's disease
}

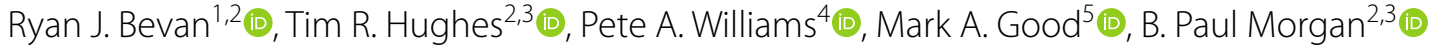 \\ and James E. Morgan ${ }^{1 *}$ (D)
}

\begin{abstract}
Neuronal dendritic and synaptic pruning are early features of neurodegenerative diseases, including Alzheimer's disease. In addition to brain pathology, amyloid plaque deposition, microglial activation, and cell loss occur in the retinas of human patients and animal models of Alzheimer's disease. Retinal ganglion cells, the output neurons of the retina, are vulnerable to damage in neurodegenerative diseases and are a potential opportunity for non-invasive clinical diagnosis and monitoring of Alzheimer's progression. However, the extent of retinal involvement in Alzheimer's models and how well this reflects brain pathology is unclear. Here we have quantified changes in retinal ganglion cells dendritic structure and hippocampal dendritic spines in three well-studied Alzheimer's mouse models, Tg2576, 3xTg-AD and APPNL-G-F. Dendritic complexity of DiOlistically labelled retinal ganglion cells from retinal explants was reduced in all three models in an age-, gender-, and receptive field-dependent manner. DiOlistically labelled hippocampal slices showed spine loss in CA1 apical dendrites in all three Alzheimer's models, mirroring the early stages of neurodegeneration as seen in the retina. Morphological classification showed that loss of thin spines predominated in all. The demonstration that retinal ganglion cells dendritic field reduction occurs in parallel with hippocampal dendritic spine loss in all three Alzheimer's models provide compelling support for the use of retinal neurodegeneration. As retinal dendritic changes are within the optical range of current clinical imaging systems (for example optical coherence tomography), our study makes a case for imaging the retina as a non-invasive way to diagnose disease and monitor progression in Alzheimer's disease.
\end{abstract}

Keywords: Alzheimer's disease, Retinal ganglion cells, Dendritic spines, DiOlistic labelling, Sholl analysis, Synaptic pruning

\section{Introduction}

Alzheimer's disease (AD) is the underlying cause of up to $70 \%$ of all dementias and estimated to afflict 40 million people worldwide by 2050 [32, 36]. AD pathology is characterised by extracellular amyloid plaques, neurofibrillary tangles, neuroinflammation and synaptic loss that ultimately result in severe brain atrophy [14, 37, 42, 49]. Synaptic dysfunction is the strongest correlator to $\mathrm{AD}$

*Correspondence: MorganJE3@cardiff.ac.uk

${ }^{1}$ School of Optometry and Vision Sciences, Cardiff University, Cardiff CF24 $4 \mathrm{HQ}, \mathrm{UK}$

Full list of author information is available at the end of the article severity and a target for therapeutic intervention $[49,51]$. Currently, the detection of early neurodegeneration is challenging and relies on insights from AD animal models that recapitulate aspects of the disease.

Visual impairment has been reported as an early symptom in some individuals diagnosed with neurodegenerative disease, including $A D[11,25]$. Visual deficits can include reduced acuity, visual field defects, changes in contrast sensitivity, impaired object recognition, and delayed visual processing [30]. While of interest, these observations have not pinpointed specific deficits in the visual pathway that consistently account for a reduction

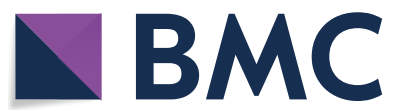

(c) The Author(s) 2020. Open Access This article is licensed under a Creative Commons Attribution 4.0 International License, which permits use, sharing, adaptation, distribution and reproduction in any medium or format, as long as you give appropriate credit to the original author(s) and the source, provide a link to the Creative Commons licence, and indicate if changes were made. The images or other third party material in this article are included in the article's Creative Commons licence, unless indicated otherwise in a credit line to the material. If material is not included in the article's Creative Commons licence and your intended use is not permitted by statutory regulation or exceeds the permitted use, you will need to obtain permission directly from the copyright holder. To view a copy of this licence, visit http://creativecommons.org/licenses/by/4.0/. The Creative Commons Public Domain Dedication waiver (http://creativeco mmons.org/publicdomain/zero/1.0/) applies to the data made available in this article, unless otherwise stated in a credit line to the data. 
in visual performance. However, retinal changes have received little attention. The retina has been proposed as a surrogate for in vivo detection and monitoring ADrelated changes in the central nervous system (CNS) since the retina can be considered an extension of the brain and is accessible for imaging [28, 29, 38]. AD retinal pathology resembles that found in the brain, including neuronal cell loss, particularly of retinal ganglion cells (RGCs) [8]. However, loss of RGCs, the output neuron of the retina, and resulting thinning of the retinal nerve fibre layer (RGC axons) suggests that these could be a meaningful index of cognitive decline and a feature in $\operatorname{AD}[31,45]$.

RGCs may be particularly susceptible to damage in the context of AD because of their intraocular unmyelinated axons, high energy demand and complex dendritic arbours [20]. The morphology of the RGC dendritic field and the disruption of glutamatergic synapses along the dendrites associate with neuronal function and dendritic degeneration correlates with visual decline [33]. RGC dendritic pruning is characterised by the loss of dendritic complexity and is a feature in retinal neurodegeneration models $[52,55]$. The underlying mechanism of dendritic loss is unclear; however, it is an important characteristic in the early stages of neurodegeneration. We have previously reported that RGC dendritic degeneration is an early pathological event in the $\mathrm{Tg} 2576$ AD mouse model compared to littermate wildtype controls [54]. However, it is not known whether these findings are reproducible across other AD mouse models, are present at different time points in disease pathogenesis, and, whether RGC dendritic loss correlates with degenerative events in the CNS in the models.

To address these issues, we characterised the RGC dendritic morphology in amyloid overexpressing (Tg2576, 3xTg-AD) and knock-in (APP $\left.{ }^{\mathrm{NL}-\mathrm{G}-\mathrm{F}}\right) \mathrm{AD}$ mouse models. Using DiOlistic labelling, a technique that is not contingent on cell health, RGCs were morphologically assessed and compared to the dendritic spine densities in the hippocampus in the same mice $[18,41,52]$. Our findings demonstrate consistent and progressive RGC degeneration from early in the disease process in both overexpressing and knock-in AD models. Retinal changes also correlated with a reduction in hippocampal spine densities in each of the models. The findings support the assessment of retinal changes to detect early-stage neurodegeneration and monitor disease progression in models and man.

\section{Methods}

\section{Animals}

All animal experiments complied with the UK Animals Scientific Procedures Act 1986 and ethical guidelines at Cardiff University. Experiments were carried out under the authority of UK Home Office licences 30/3220, P8159A562 and 30/03313. Mice were grouphoused where possible in environmentally enriched cages with food and water ad libitum in a 12-h light/ dark cycle. Tg2576 (In-house line, (strain: B6; SJLTg(APPSWE)2576Kha), 3xTg-AD (The Jackson Laboratory, (strain 34830-JAX: B6; 129-Tg(APPSwe,

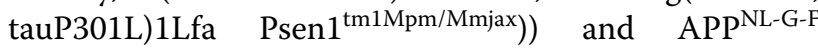

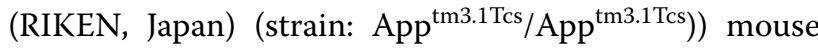
models were analysed with $\operatorname{Tg} 2576$ compared to wildtype littermate controls (WT Control) and the 3xTg-AD and $\mathrm{APP}^{\mathrm{NL}-\mathrm{G}-\mathrm{F}}$ models compared to C57BL/6J (B6/J Control, in house colony). It was not possible to compare $3 \mathrm{xTg}$ $\mathrm{AD}$ and $\mathrm{APP}{ }^{\mathrm{NL}-\mathrm{G}-\mathrm{F}}$ mice to littermate controls; instead, we compared our observations to C57BL6/J mice (B6/J Controls) since the APP ${ }^{\mathrm{NL}-\mathrm{G}-\mathrm{F}}$ model are based on the same background. Littermate controls for the 3xTg-AD model are not available due to the mixed background and shotgun approach used to generate this model. The Jackson Laboratory offer an approximate control (B6129SF2/J, Stock No: 101045) for the 3xTg-AD strain, however, this strain is known to develop other confounding features. Both sexes were analysed for B6/J Control, $3 x T g-A D$ and $A P P^{N L-G-F}$; however, only males were available for the Tg2576 model. Table 1 provides details on the number of mice, RGCs and hippocampal dendritic segments analysed from each model at 6-7 months and 12 months. The specific number of mice, RGCs and hippocampal dendritic segments are included where appropriate with the associated figures.

\section{Tissue harvest}

For retinal analysis, eyes were enucleated and transferred to chilled $4{ }^{\circ} \mathrm{C}$ HBSS (Hank's Balanced Salt Solution), punctured with a needle at the limbus and the cornea, lens, vitreous and sclera removed. Retinal explants were flat-mounted ganglion cell layer up. For hippocampal analysis, whole brains were removed and cut sagittally in chilled $4{ }^{\circ} \mathrm{C}$ HBSS. In one hemisphere, parasagittal hippocampal regions were sliced $(200 \mu \mathrm{m})$ in a septal to temporal progression using a Mcllwain tissue chopper. The total time for retinal explant preparation from both eyes and hippocampal slicing in a single mouse was less than $10 \mathrm{~min}$, since time is critical for DiOlistic labelling efficiency.

\section{DiOlistic preparation and neuronal labelling}

Fresh retinal explants and hippocampal slices prepared as above were transferred to glass slides and subjected to gene gun (BioRad) DiOlistic labelling of neurons [10, 47, 50]. In brief, Ethylene tetrafluoroethylene (ETFE) tubing was coated with $1.67 \mu \mathrm{m}$ tungsten particles coated with 1,1'-Dioctadecyl-3,3,3',3'-Tetramethylindocarbocyanine 
Table 1 Number of mice, RGCs and hippocampal dendritic segments across all models analysed

\begin{tabular}{|c|c|c|c|c|c|c|}
\hline \multirow[t]{2}{*}{ Model } & \multicolumn{3}{|c|}{ Age analysed: 6-7 months } & \multicolumn{3}{|c|}{ Age analysed: 12 months } \\
\hline & Mice (n) & RGCs (n) & $\begin{array}{l}\text { Hippocampal dendritic } \\
\text { segments }(n)\end{array}$ & Mice (n) & RGCs (n) & $\begin{array}{l}\text { Hippocampal } \\
\text { dendritic segments } \\
\text { (n) }\end{array}$ \\
\hline WT Control & $x$ & $x$ & $x$ & 7 & 74 & 71 \\
\hline $\operatorname{Tg} 2576$ & $x$ & $x$ & $x$ & 8 & 58 & 85 \\
\hline B6/J Control & 6 & 58 & 47 & 10 & 114 & 106 \\
\hline $3 \times \operatorname{Tg}-A D$ & 9 & 99 & 77 & 12 & 144 & 223 \\
\hline APP NL-G-F & 7 & 94 & 46 & 6 & 80 & 130 \\
\hline Total & 22 & 251 & 170 & 43 & 470 & 615 \\
\hline
\end{tabular}

WT wildtype, $R G C s$ retinal ganglion cells

Perchlorate (DiI, Life Technologies) and 3,3'Dioctadecloxacarbocyanine Perchlorate (DiO, Life Technologies). Dye coated ETFE 'bullets' were cut at $1.2 \mathrm{~cm}$, loaded into the gene gun and fired onto the slides at a pressure of $100-120$ psi through a $3.0 \mu \mathrm{m}$ membrane (BD Falcon $3.0 \mu \mathrm{m}, \mathrm{BD}$ Biosciences). Slides were then immersed in Neurobasal-A medium (Life Technologies) for $20 \mathrm{~min}$ at $37{ }^{\circ} \mathrm{C}$ with $5 \% \mathrm{CO}_{2}$. Dye staining was checked under a fluorescence microscope to confirm neuron labelling then slides were fixed in 4\% PFA (paraformaldehyde) for a minimum of $30 \mathrm{~min}$, with subsequent nuclei labelling with Hoechst 33258. Slides were coverslipped with FluorSave and stored in the dark at $4{ }^{\circ} \mathrm{C}$ until analysis.

\section{Confocal imaging}

All confocal images were captured using a Leica SP8 Lightning confocal microscope. RGCs were identified by their morphology and relative position in the retina, i.e. in the ganglion cell layer, characteristic dendritic field and a clear axon projecting towards the optic nerve. RGCs with overlapping dendritic fields that prevented singlecell delineation were excluded from the analysis. Dendritic arbours were imaged using $20 \times$ objective (z-axis, interval $1 \mu \mathrm{m}$ ). Hippocampal dendrites (CA1 field) were selected based on the minimal overlap of adjacent cells. CA1 apical dendritic spines were imaged at $63 \times$ objective (z-axis, interval $0.2 \mu \mathrm{m}$ ) using Lightning Deconvolution (Leica). Typically, each hippocampal slice yielded at least one CA1 neuron suitable for imaging; 10-15 images/neurons were imaged per mouse.

\section{Neuronal reconstruction}

All confocal images were analysed using Imaris software (version 9.2, Bitplane, Zurich, Switzerland). RGC dendritic fields and hippocampal dendrites were reconstructed using the Filament Tracer module with default thresholding based around a 'region of interest', i.e. the dendritic field. All dendritic arbours were automatically traced within the software with any incorrect tracing, e.g. adjacent cells or dye debris manually removed. The associated statistical parameters were exported from Imaris for data analysis with Sholl analysis used for a measure of dendritic complexity (at set intervals of $10 \mu \mathrm{m})$. Dendritic spines were reconstructed using the Filament tracer in the same process as retinal ganglion cells; however smaller 'regions of interest', i.e. dendritic segments typically of $30 \mu \mathrm{m}$ were analysed. Spines were detected using the Filament Tracer module and classified using the SpineClassifer MATLAB extension. Spine types were distinguished on the basis of spine length and spine head size.

\section{Retinal ganglion cell receptive field classification}

Retinal ganglion cells were classified based on their dendritic lamination into the inner plexiform layer $[1,53]$. Dendrites projecting into the sublamina b (closest to the ganglion cell layer) were termed ON-centre; conversely, dendrites projecting into the sublamina a were termed OFF-centre [56].

\section{Nuclei counts}

The number of nuclei in the ganglion cell layer were quantified from Hoechst labelling from the DiOlistic RGC confocal images. All RGC images with Hoechst 33258 labelling were quantified using the Spots function in Imaris and averaged to obtain a nuclei ganglion cell layer count per animal. Parameters were kept consistent for all quantifications.

\section{Statistics}

Data are represented as individually reconstructed retinal ganglion cells and dendritic segments for spine densities collected for each group. Statistical analyses were performed using GraphPad Prism software (version 8) with the statistical tests and details of data reported in each figure legend where appropriate. Data were analysed 
using the Mann-Whitney $U$ test, 1-way analysis of variance (Kruskal-Wallis test) using Dunn multiple comparisons post-test or two-way ANOVA, as appropriate. Associations between pathological variables were tested by Spearman analysis. Significant results are denoted as follows: $*=p<0.05, *=p<0.01, \quad * * * *=p<0.001$, $* * * * * * 0<0.0001$.

\section{Results}

Retinal ganglion cell degeneration is a common feature of the Tg2576, 3xTg-AD and APP ${ }^{\mathrm{NL}-G-\mathrm{F}}$ AD mouse models

We first sought to determine whether RGC dendritic degeneration occurred in Tg2576, 3xTg-AD and $\mathrm{APP}^{\mathrm{NL}-\mathrm{G}-\mathrm{F}} \mathrm{AD}$ mouse models at 12 months, a time point when these models have been demonstrated to have hippocampal and behavioural degenerative changes that are indicative of AD-like pathology. Sholl analysis demonstrated significant reductions in dendritic complexity in all three $\mathrm{AD}$ models compared to respective age-matched wildtype control mice (littermate controls for Tg2576 mice and B6/J controls for 3xTg-AD and APP ${ }^{\mathrm{NL}-\mathrm{G}-\mathrm{F}}$ mice) (Fig. 1a-e). Sub-analysis, according to dendrite branch hierarchy, showed preservation of primary dendrites across the three AD models. However, 3xTg-AD RGCs showed significant secondary dendritic loss, and all models showed tertiary and quaternary dendritic pruning (Fig. 1f). Overall the area under the Sholl curve (AUC; a global measure of dendritic complexity) showed significant pruning in all three $\mathrm{AD}$ models, with the greatest dendritic loss observed in the APP ${ }^{\mathrm{NL}-\mathrm{G}-\mathrm{F}}$ retina (Fig. 1g). These reductions were matched by a decrease in the peak of the Sholl curve and the total dendrite length (Fig. 1hi). Notably, the dendritic changes occurred in the absence of significant cell loss in the ganglion cell layer (GCL, Fig. 1j). We also observed dendritic varicosities (swelling of the dendrites) which coincided with an increased diameter of the dendrites situated around and after the peak of the Sholl curve (branching levels 4-7) in RGCs from all AD model mice (Fig. 2).

We were able to assess RGC dendritic structure in 6-7-month and 12 month 3xTg-AD, APP ${ }^{\mathrm{NL}-\mathrm{G}-\mathrm{F}}$ and B6/J Control mice (Fig. 3). In 3xTg-AD mice at 6-7 months, RGCs showed no excess dendritic pruning compared to $\mathrm{B} 6 / \mathrm{J}$ Control; however, at 12 months $3 \mathrm{xTg}-\mathrm{AD}$ mice demonstrated significantly greater dendritic loss compared to controls (Fig. 3a, b). In comparison to B6/J Control, APP ${ }^{\mathrm{NL}-\mathrm{G}-\mathrm{F}}$ mice at 6-7 months showed significantly greater RGC dendritic degeneration with a reduced Sholl profile corresponding to the highest branched areas of the dendritic field; comparison with $\mathrm{APP}^{\mathrm{NL}-\mathrm{G}-\mathrm{F}}$ mice at 12 months showed significantly increased dendritic loss with age (Fig. 3c, d). In B6/J Control mice, RGC dendritic complexity was not different between 6-7 months and
12 months (Fig. 3e). These findings were also supported by quantitative assessments of the Sholl AUC, the peak of the Sholl intersections, and the total dendritic length (Fig. $3 \mathrm{f}-\mathrm{h}$ ) which demonstrate that increased RGC dendritic atrophy occurs in AD model mice and progressively worsens with age.

ON-centre specific RGCs are more affected in the AD model mouse retina

We next investigated whether RGCs changes were influenced by RGC type. RGCs with dendritic lamination in inner plexiform layer (IPL) sublamina $b$ are classified as $\mathrm{ON}$-centre and those with dendrites in sublamina $a$ are classified as OFF-centre. RGCs were compared across all three AD models at 12 months (Fig. 4). Significant ON-centre RGC dendritic loss was present in all three AD models (Fig. $4 \mathrm{a}-\mathrm{e}$ ). APP ${ }^{\mathrm{NL}-\mathrm{G}-\mathrm{F}}$ and, to a lesser degree 3xTg-AD mice demonstrated significant dendritic loss compared to controls in OFF-centre RGCs; a non-significant trend of increased dendritic loss in the OFF-centre RGCs was seen in Tg2576 mice compared to controls (Fig. $4 \mathrm{f}-\mathrm{j}$ ). Collectively, these data show a greater susceptibility for ON-centre RGC degeneration across the three AD models.

\section{Retinal ganglion cell dendritic impairment is more prominent in male $A D$ mice}

Since gender-related differences in susceptibility have been reported in $\mathrm{AD}$ models, we next determined whether this was a factor influencing the degree of RGC dendritic pruning in the $3 \times \mathrm{Tg}-\mathrm{AD}$ and $\mathrm{APP}^{\mathrm{NL}-\mathrm{G}-\mathrm{F}}$ models where sufficient mice of both genders were available for analysis. Both male and female $3 \mathrm{xTg}-\mathrm{AD}$ and $\mathrm{APP} \mathrm{P}^{\mathrm{NL}-\mathrm{G}-\mathrm{F}}$ models demonstrated significant RGC dendritic loss compared to gender-matched B6/J Control (Fig. 5a-i). There were no morphological differences in RGCs between male and female B6/J Control mice (Fig. 5g). In contrast, we observed increased degeneration in RGCs from male compared to female mice in both the 3xTg-AD and APP ${ }^{\mathrm{NL}-\mathrm{G}-\mathrm{F}}$ models, the former exhibiting the largest difference between genders (Fig. 5h, i). These findings were supported by quantitative measures of the Sholl AUC (Fig. 5j), the peak of the Sholl curve (Fig. 5k), and total dendrite length (Fig. 5l).

\section{Retinal pathology reflects hippocampal dendritic spine loss in the AD models}

To determine the relationship between retinal and CNS (hippocampal) neurodegeneration, we measured, in the same mice, dendritic spines in the hippocampus of Tg2576, 3xTg-AD and APP ${ }^{\text {NL-G-F }}$ mice at 12 months (Fig. 6a). All three AD models displayed overall reductions in spine density on CA1 hippocampal neurons 


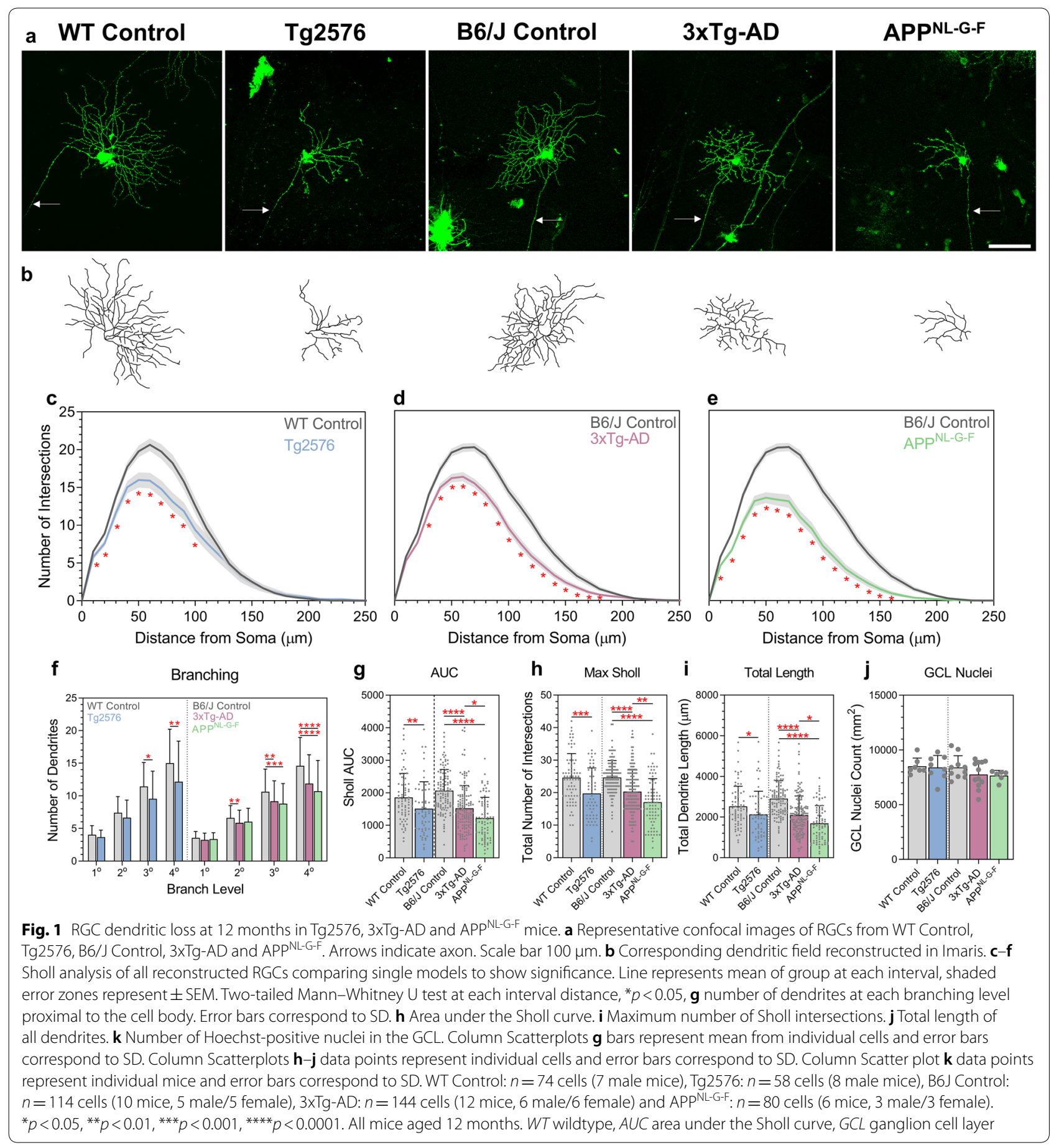

compared to respective wildtype controls, with $3 x \mathrm{Tg}$ AD mice the most severely affected (Fig. 6b). Dendritic spines can be subdivided based on morphological differences that reflect the functional diversity of the synapses [39]. Classifying the dendritic spines based on morphology revealed differences between the models. Thin spines showed a significant reduction in all models, while only
3xTg-AD mice demonstrated a significant reduction in the number of stubby spines, and mushroom spines were unaffected across all models (Fig. 6c-e). Loss of spines, significantly correlated with RGC dendritic loss in the $3 x T g-A D$ and $A P P^{N L-G-F}$ mice when separated on morphology, thin spines showed the best correlation (Fig. 6f-g). We also analysed CA1 spine densities 


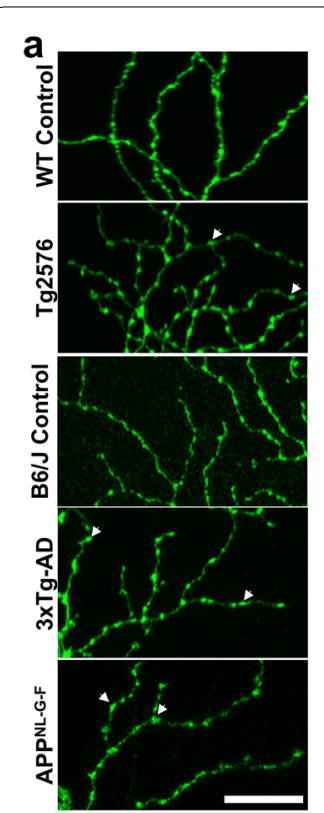

\section{b}

\section{Dendrite Varicosity}

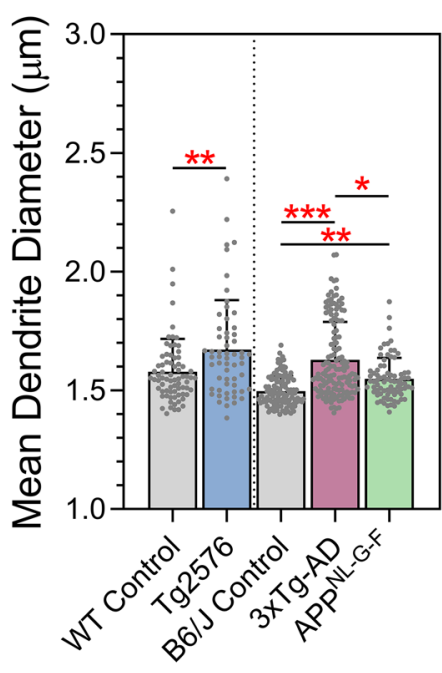

Fig. 2 RGC dendritic diameter increases in AD mice. a Representative confocal images of RGC dendrites from WT Control, Tg2576, B6J Control $3 \times T_{9}-A D$ and APP ${ }^{N L-G-F}$. Arrows indicate beading and swelling of dendrites. Scale bar $25 \mu \mathrm{m}$. b Dendrite varicosity, assessed by measurement of dendrite diameter. Column Scatterplots: data points represent individual cells and error bars correspond to SD. WT Control: $n=74$ cells ( 7 male mice), Tg2576: $n=58$ cells ( 8 male mice), B6J Control: $n=114$ cells (10 mice, 5 male/5 female), 3xTg-AD: $n=144$ cells ( 12 mice, 6 male/ 6 female) and APP ${ }^{N L-G-F}: n=80$ cells ( 6 mice, 3 male/3 female). All mice aged 12 months. ${ }^{*} p<0.05$, ${ }^{* *} p<0.01$, ${ }^{* * *} p<0.001,{ }^{* * *} p<0.0001$

in $\mathrm{B} 6 / \mathrm{J}$ Control, 3xTg-AD and APP ${ }^{\mathrm{NL}-\mathrm{G}-\mathrm{F}}$ mice between the ages of 6-7 months (Fig. 6h-k). At this age, overall spine density was only reduced in $\mathrm{APP} \mathrm{NL}^{\mathrm{NL}-\mathrm{F}}$ mice; again thin spines were the most affected. In the 3xTg-AD mice, despite no apparent overall spine reduction, the number of stubby spines was significantly decreased whilst the density of mushroom spines was increased compared to B6/J Controls. These data demonstrate that hippocampal spine loss is a consistent feature in all models and correlates with RGC changes.

\section{Discussion}

Dendritic and spine loss are among the earliest events in neurodegeneration. While regions such as the hippocampus and cortex, are primary sites of pathology in $\mathrm{AD}$, other parts of the CNS, including the retina, are affected $[15,26]$. AD-relevant changes in the retina in AD models and human disease offer the prospect of noninvasive monitoring through in vivo imaging of retinal pathology as a tool to diagnose disease, monitor progression and test the efficacy of AD treatments; however, to date, reports of retinal pathology in humans and animal models have been few and inconsistent [5]. Justino et al. [22] suggested no retinal dysfunction based on normal scotopic and photopic flash electroretinograms (fERGs) and oscillatory potentials (OPs) in AD cases. While others report the absence of amyloid deposits and tau pathology in the retinas of post mortem AD cases, despite the detection in the brain [16]. In the retina of APP/PS1 mice, Chidlow et al. [5] found no relevant retinal pathology despite the presence of robust brain amyloid pathology, however in the same model KoronyoHamaoui et al. [23] report the in vivo detection of amyloid plaques in the retina that accumulated with disease progression. We have previously reported a preliminary study that documented reduced RGC dendritic complexity in the Tg2576 AD mouse model [54]; RGC dendritic integrity was reduced at 14 months. Here we have confirmed and extended these findings; we found significant RGC dendritic loss in Tg2576 mice compared with agematched littermate controls at 12 months that occurred alongside observed hippocampal spine loss in the same animals.

In order to explore whether this observation could be general in nature, we next examined retinal and hippocampal pathology in two other mouse AD models, the widely used 3xTg-AD model (transgenic expression of three risk genes; APP Swedish, MAPT P301L, and PSEN1 M146V) and the recently described APP ${ }^{\mathrm{NL}-\mathrm{G}-\mathrm{F}}$ model (knock-in of a humanized $A \beta$ region including the Swedish "NL", the Iberian " $F$ ", and the Arctic "G" mutations). It was not possible to compare $3 \mathrm{xTg}-\mathrm{AD}$ mice to littermate controls because of the complex background of this strain as has been noted by The Jackson Laboratory (https://www.jax.org/strain/101045), therefore we pragmatically chose to use C57BL6/J mice (B6/J) as controls. Animal breeding constraints prevented the use of littermate controls for the APP ${ }^{\mathrm{NL}-\mathrm{G}-\mathrm{F}}$ mice; these are on the B6/J background so B6/J mice were used as controls. We selected DiOlistic labelling as a technique for measurement of dendritic complexity because the DiOlistic labelling of individual cells is not contingent on the health of the cell [19]. Using other methods such as the expression of fluorescent proteins can be problematic in chronic disease models since healthier neurons may show higher levels of expression, reducing sensitivity for detecting degenerating neurons. We have previously reported this effect when comparing degeneration in retinal ganglion cells labelled with YFP compared with DiI in a chronic murine glaucoma model [52]. Using multiple morphological parameters, we observed significant RGC dendritic loss compared to B6/J controls at 12 months in the $3 x T g-A D$ and $A P P^{N L-G-F}$ models, with the greatest severity seen in the APP ${ }^{\mathrm{NL}-\mathrm{G}-\mathrm{F}}$ mice. At 6-7 months there was no significant loss of RGC dendrites in the 3xTg-AD 


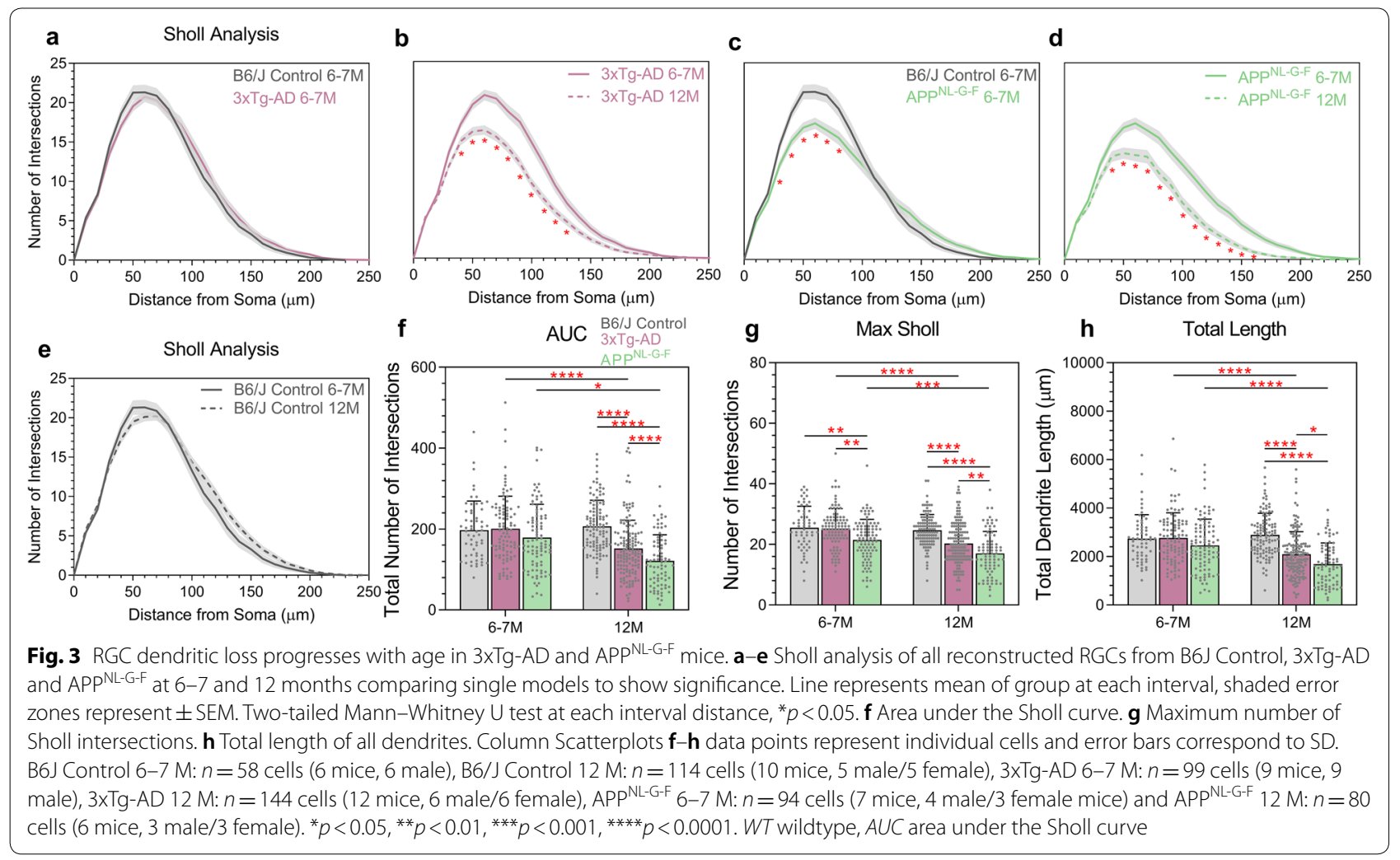

mice; in contrast, APP ${ }^{\mathrm{NL}-\mathrm{G}-\mathrm{F}}$ mice showed significant RGC dendritic loss even at this early age, though not to the extent seen at 12 months in this model, confirming disease progression with age in both models. The identification of RGC dendritic loss may be reflected in a reduction in the thickness of the retinal layers. Although we did not measure this, others have reported that $3 x T g-A D$ mice display thinning of the retinal sublayers, including the GCL and IPL, which correlate with changes occurring the brain [7]. We also observed significant swelling and beading of the dendrites in the RGCs from AD models, possibly indicating mitochondrial dysfunction [12]. Of note, there was no significant reduction in number of nuclei in the ganglion cell layer implying that the number of RGC's were unaffected. In all three models, RGC dendritic loss occurred in parallel with hippocampal dendritic spine loss; these correlated strongly in the 3xTg-AD and APP ${ }^{\text {NL-G-F }}$ mice.

We next determined whether there was any selectivity for specific RGC subtypes in dendritic loss. RGCs can be categorised as ON-centre or OFF-centre, based on their response to illumination; these can be distinguished morphologically, ON-centre RGC dendrites projecting into sublamina b while OFF-centre RGC dendrites project into sublamina a [56]. In all three models, the loss of dendrites in ON-centred RGCs was more pronounced than in OFF-centre RGCs; ON-centre RGCs are depolarised by illumination. Their selective loss in the models may be

\section{(See figure on next page.)}

Fig. 4 RGC receptive field classification impacts on dendritic loss. a-b Representative confocal images of ON-centre RGCs from WT Control, Tg2576, B6 J Control 3xTg-AD and APPN-G-F with corresponding Imaris reconstructions. Arrows indicate axons. Scale bar $100 \mu \mathrm{m}$. c-e Sholl analysis of reconstructed ON-centre RGCs comparing single models to show significance. Two-tailed Mann-Whitney U test at each interval distance, ${ }^{*} p<0.05$. f-g Representative confocal images of OFF-centre RGCs from WT Control, Tg2576, B6J Control, 3xTg-AD and APPNL-G-F with corresponding Imaris reconstructions. Arrows indicate axons. Scale bar $100 \mu \mathrm{m}$. h-j Sholl analysis of reconstructed OFF-centre RGCs comparing single models to show significance. Two-tailed Mann-Whitney $U$ test at each interval distance, ${ }^{*} p<0.05$. Sholl analysis line represents mean of group at each interval, shaded error zones represent \pm SEM. WT Control ON: $n=43$ cells, WT Control OFF: $n=31$ cells (7 male mice) Tg2576 ON: $n=30$ cells, Tg2576 OFF: $n=28$ cells ( 8 male mice); B6/J Control ON: $n=56$ cells, B6/J Control OFF: $n=58$ cells ( 10 mice, 5 male/ 5 female); $3 \times \operatorname{Tg}-A D$ ON: $n=69$ cells, 3xTg-AD OFF: $n=75$ cells ( 12 mice, 6 male/ 6 female); APP ${ }^{N L-G-F}$ ON: $n=38$ cells, APP ${ }^{N L-G-F}$ OFF: $n=41$ cells ( 6 mice, 3 male/3 female). All mice aged 12 months. WT wildtype 


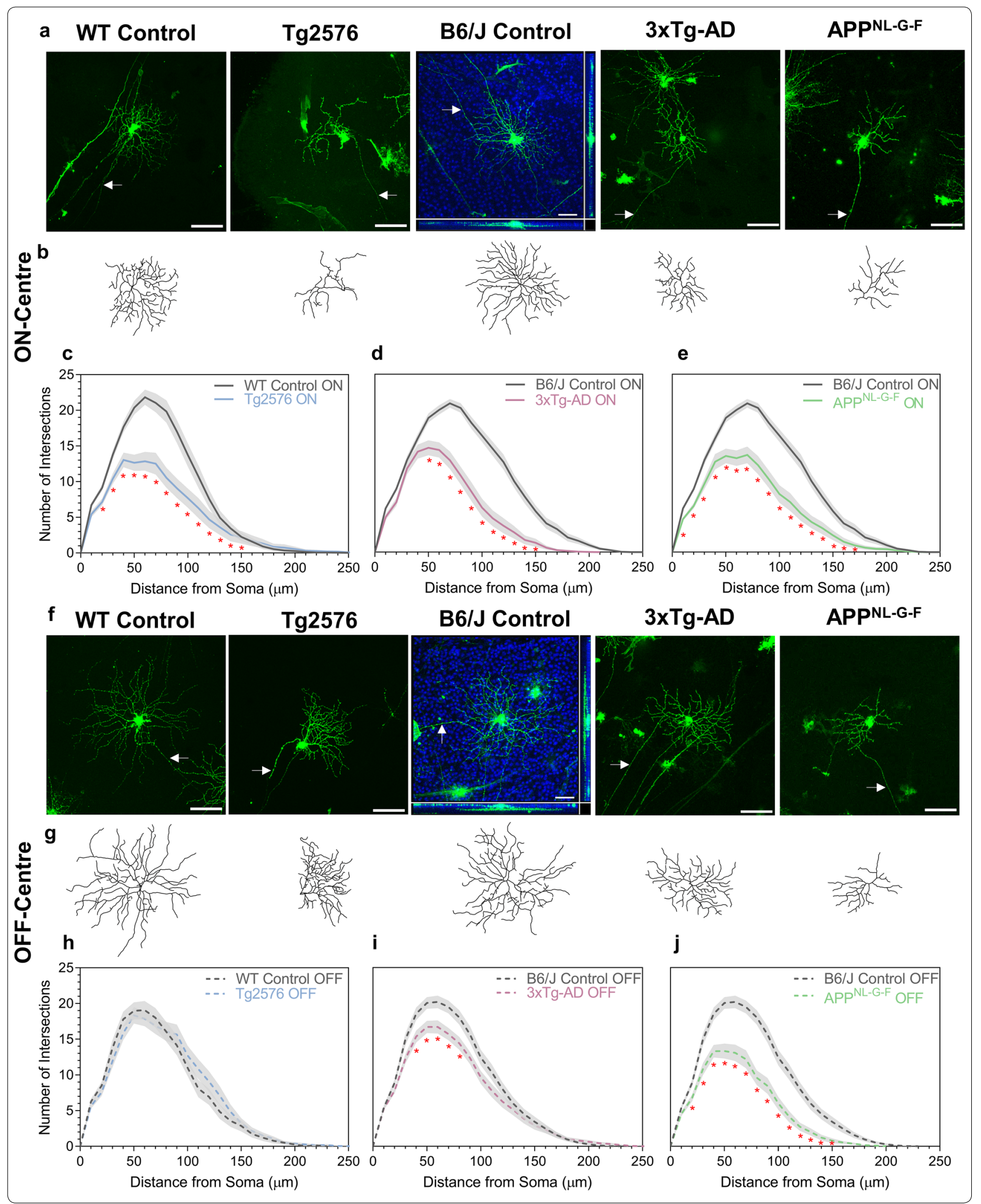


a consequence of their higher energy demand and higher number of excitatory glutamatergic synapses [53].

Loss of hippocampal dendritic spines is a key hallmark of many AD models with spine loss particularly acute in the vicinity of amyloid plaques [46]. Dendritic spines can be subdivided into mushroom, stubby and thin categories based on morphology; [3] these morphological differences reflect functional diversity [39]. Thin spines are highly dynamic, capable of activity-dependent formation of new synapses during the process of learning. Loss of thin spines is associated with deficits in spatial learning and memory and has been reported in a range of CNS regions and contexts, such as the prefrontal cortex and hippocampus during normal ageing [57]. We used the SpineClassifier function in Imaris to label spine types on the basis of spine length and head size and re-analysed the hippocampal spine loss data. In each of the three AD models we observed a clear selective effect, a significant loss of thin spines with preservation of mushroom and stubby spines. Thin spine loss was particularly strongly correlated with the extent of RGC dendritic atrophy in the $3 \times \mathrm{Tg}-\mathrm{AD}$ and $\mathrm{APP} \mathrm{P}^{\mathrm{NL}-\mathrm{G}-\mathrm{F}}$ mice when compared with B6/J Controls. These findings reinforce the critical importance of dendritic spine loss as part of AD pathology; the observed thin spine selectivity fits with deficits in learning and memory in the models and in AD. Our results are supported by other studies that report dendritic spine loss, particularly in the hippocampus, of AD models $[4,35,58]$. The strong correlation with RGC degeneration indicates that retinal measures can provide an index of synaptic status in the hippocampus during AD pathology.

Gender variation in the 3xTg-AD model has been reported in the literature with more consistent pathology found in females [2]. We were able to separately measure RGC dendritic degeneration in male and female 3xTg$\mathrm{AD}$ and $\mathrm{APP} \mathrm{P}^{\mathrm{NL}-\mathrm{G}-\mathrm{F}}$ mice at 12 months; surprisingly, RGC dendritic loss was more pronounced in males in both models, more obviously in the 3xTg-AD model. Previous studies have reported other retinal pathologies in the 3xTg-AD model, including amyloid plaques, inflammation and microglial activation that could contribute to the observed RGC dendritic changes and gender differences in this model $[13,40]$. The reason for these gender-dependent effects on RGC degeneration are unclear; however, given the known role of complement in synaptic loss in AD models $[17,43,44,55]$ and in synapse elimination in the CNS [48] we suggest that a possible driver of observed gender differences relate to differences in complement activity. Numerous studies have demonstrated gender differences in complement activity across mouse strains with male mice consistently showing more complement activity that females [24]; this would translate into more efficient complement activation at the synapse and greater synapse loss in male mice. Our (unpublished) analyses of the impact of complement gene deletion on synaptic loss in mouse AD models support this suggestion. Our study demonstrates the occurrence of RGC degeneration as an early and well-correlated marker of hippocampal neurodegeneration in both overexpressing and knock-in mouse models of AD. These findings provide vital evidence of significant retinal pathology in $A D$ mouse models and reinforces the potential of monitoring disease by imaging the retina in human neurodegenerative diseases. There are limitations in extrapolating from models to human disease; hence it is possible that some of the reported retinal changes may not be reflected in the human disease [6]. Our demonstration that RGC dendritic degeneration occurs in the retina of knock-in $\mathrm{APP}^{\mathrm{NL}-\mathrm{G}-\mathrm{F}}$ mice, the best available model for amyloidosis in the human disease because it does not suffer from overexpression artefacts, supports relevance. RGCs from APP ${ }^{\mathrm{NL}-\mathrm{G}-\mathrm{F}}$ mice progressively degenerated with age and showed signs of dendritic changes early in the disease course that correlated with hippocampal changes and were in line with the known disease progression in the model.

Our data support the development of clinical imaging strategies targeting the inner plexiform layer (IPL), the region where RGC dendrites are located, to provide a non-invasive diagnostic tool and correlate of synaptic degeneration in the CNS in AD. RGC degeneration in the IPL can be imaged in vivo at high resolution using optical coherence tomography (OCT).

\footnotetext{
(See figure on next page.)

Fig. 5 Gender influences the extent of RGC dendritic impairment at 12 months in the 3xTg-AD and APP ${ }^{\mathrm{NL}-G-F}$ mice. a-i Sholl analysis of reconstructed RGCs from male and female mice compared to B6/J Control and within each model. a represents all the male data, $\mathbf{d}$ represents all the female data, $\mathbf{b}-\mathbf{c}$, and $\mathbf{e}-\mathbf{i}$ compare single models to show significance. Two-tailed Mann-Whitney $\mathrm{U}$ test at each interval distance, ${ }^{*} p<0.05$. Sholl analysis line represents mean of group at each interval, shaded error zones represent \pm SEM. $\mathbf{j}$ Area under the Sholl curve. Two-way ANOVA: Interaction: $F(2,332)=3.629, p=0.0276$; Genotype: $F(2,332)=42.38, p<0.0001$; Gender: $F(1,332)=5.701, p=0.0175$. $\mathbf{k}$ Maximum number of Sholl intersections. Two-way ANOVA: Interaction: $F(2,332)=2.490, p=0.0845$; Genotype: $F(2,332)=32.72, p<0.0001$; Gender: $F(1,332)=4.182$, $p=0.0416$. I Total length of all dendrites. Two-way ANOVA: Interaction: $F(2,332)=3.213, p=0.0415$; Genotype: $F(2,332)=47.40, p<0.0001$; Gender: $F(1,332)=6.137, p=0.0137$. Column Scatterplot $\mathbf{j}-\mathbf{I}$ data points represent individual cells and error bars correspond to SD. B6J Control male: $n=64$

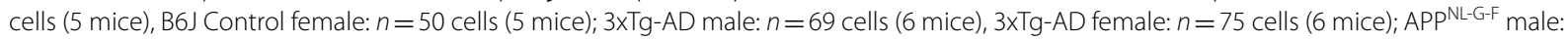
$\mathrm{n}=45$ cells $\left(3\right.$ mice), APP ${ }^{\mathrm{NL}-\mathrm{G}-\mathrm{F}}$ female: $\mathrm{n}=35$ cells $\left(3\right.$ mice). All mice aged 12 months. ${ }^{*} p<0.05,{ }^{* *} p<0.01,{ }^{* * *} p<0.001,{ }^{* * * *} p<0.0001$. AUC area under the Sholl curve
} 


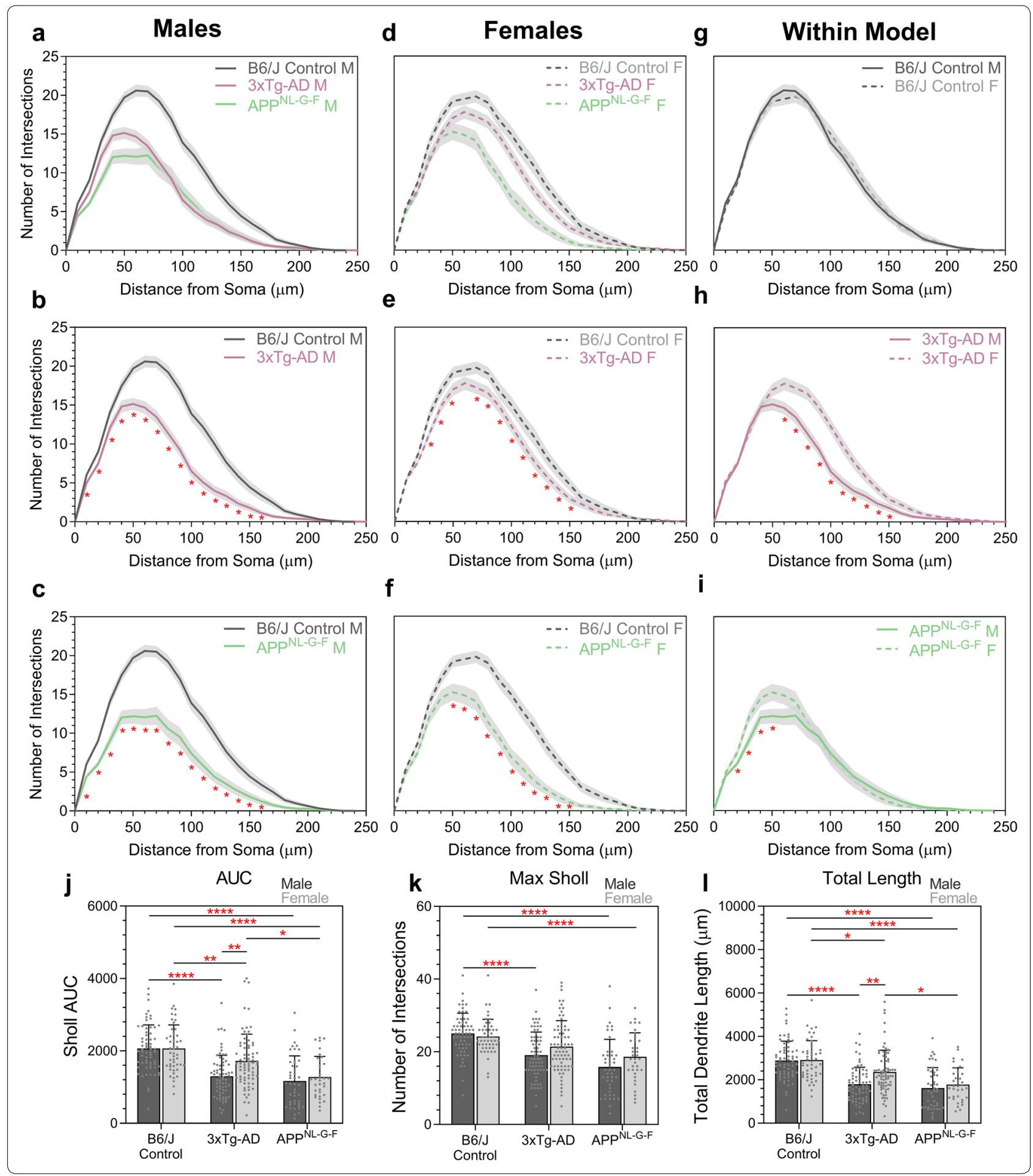

With the development of broad-spectrum light sources, OCT can detect changes in the optical scattering characteristic of neurons undergoing degeneration and even changes in neuronal membrane refractive index that correlate with neuronal activity $[21,27,34]$. The demonstration that retinal changes occur in both the $3 x T g-A D$ and APP ${ }^{N L-G-F}$ AD models early in the disease process and correlate with synaptic dysfunction, an early pathological event preceding neuronal cell loss and amyloid deposition in $\mathrm{AD}$ [9], indicates that retinal 


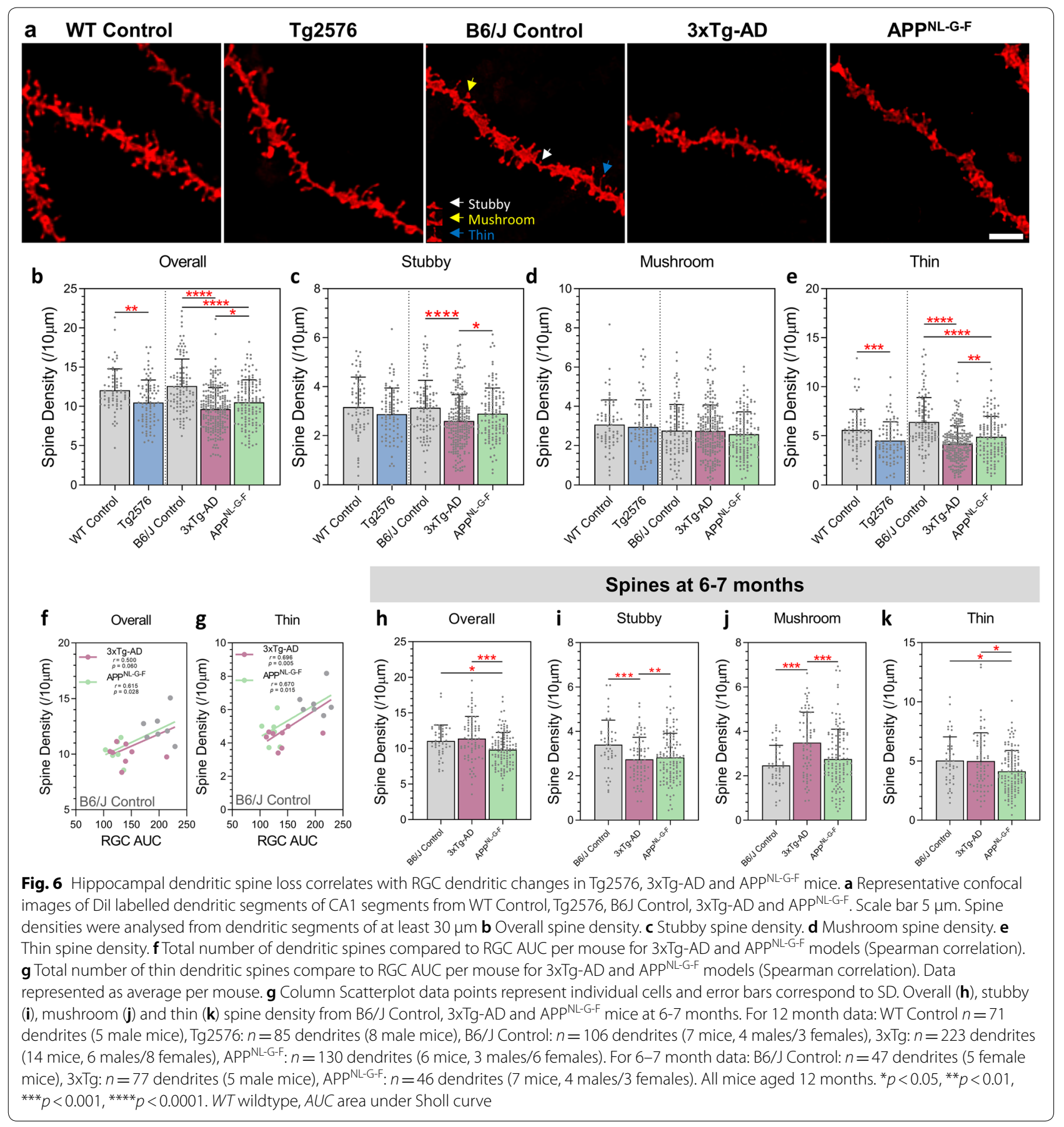

imaging has the potential to provide insights into the CNS health in mild cognitive impairment and the early stages of $\mathrm{AD}$.

\section{Abbreviations}

AD: Alzheimer's disease; CNS: Central nervous system; RGCs: Retinal ganglion cells; IPL: Inner plexiform layer; OCT: Optical coherence tomography; GCL: Ganglion cell layer.

\section{Acknowledgements}

The authors would like to thank Anthony Hayes and Mark Isaacs at Bioimaging Research Hub at Cardiff School of Biosciences for assistance and use of Imaris funded by Cardiff University's Research Infrastructure Fund.

\section{Authors' contribution}

All authors contributed to the study conception and design. Material preparation, data collection and analysis were performed by RJB. Assistance with animals was provided by TRH and MAG. The manuscript was written by RJB, PAW, BPM and JEM are all authors who read and approved the final manuscript. 


\section{Funding}

This work was supported by the UK Dementia Research Institute which receives its funding from UK DRI Ltd, funded by the UK Medical Research Council, Alzheimer's Society and Alzheimer's Research UK (MC_PC_17112). BPM. is supported by a Programme Grant from the MRC-funded UK Dementia Research Institute Cardiff. PAW. is supported by the Karolinska Institutet in the form of a Board of Research Faculty Funded Career Position and by St. Erik Eye Hospital philanthropic donations, Vetenskapsrådet (2018-02124).

\section{Data availability}

The datasets used and/or analysed during the current study are available from the corresponding authors upon reasonable request.

\section{Ethics approval and consent to participate}

All experiments were conducted under the UK Animals Scientific Procedures Act 1986 and ethical guidelines at Cardiff University under the authority of UK Home Office licences 30/3220, P8159A562 and 30/03313.

\section{Consent for publication}

Not applicable.

\section{Competing interests}

The authors declare that they have no competing interests.

\section{Author details}

${ }^{1}$ School of Optometry and Vision Sciences, Cardiff University, Cardiff CF24 $4 \mathrm{HQ}$, UK. ${ }^{2}$ UK Dementia Research Institute, Cardiff University, Cardiff, UK. ${ }^{3}$ Systems Immunity Research Institute, Cardiff University, Cardiff, UK. ${ }^{4}$ Department of Clinical Neuroscience, Division of Eye and Vision, St. Erik Eye Hospital, Karolinska Institutet, Stockholm, Sweden. ${ }^{5}$ School of Psychology, Cardiff University, Cardiff, UK.

Received: 17 November 2020 Accepted: 23 November 2020 Published online: 07 December 2020

\section{References}

1. Baden T, Berens P, Franke K, Rosón MR, Bethge M, Euler T (2016) The functional diversity of retinal ganglion cells in the mouse. Nature 529:345350. https://doi.org/10.1038/nature16468

2. Belfiore R, Rodin A, Ferreira E, Velazquez R, Branca C, Caccamo A, Oddo S (2019) Temporal and regional progression of Alzheimer's disease-like pathology in 3xTg-AD mice. Aging Cell 18:1-13. https://doi.org/10.1111/acel.12873

3. Berry KP, Nedivi E (2017) Spine dynamics: are they all the same? Neuron 96:43-55. https://doi.org/10.1016/j.neuron.2017.08.008

4. Bittner T, Fuhrmann M, Burgold S, Ochs SM, Hoffmann N, Kretzschmar H, Laferla FM, Herms J (2010) Multiple events lead to dendritic spine loss in triple transgenic Alzheimer's disease mice. PLoS ONE 5:1-9. https://doi. org/10.1371/journal.pone.0015477

5. Chidlow G, Wood JPM, Manavis J, Finnie J, Casson RJ (2017) Investigations into retinal pathology in the early stages of a mouse model of Alzheimer's disease. J Alzheimer's Dis 56:655-675. https://doi.org/10.3233/JAD160823

6. Chintapaludi S, Carter AU, Jackson H, Acklin C, Wang X, Sasner M, Carter G, Howell G (2020) Staging Alzheimer's disease in the brain and retina of B6.APP/PS1 mice by transcriptional profiling. J Alzheimer's Dis 73:1421-1434. https://doi.org/10.1101/741421

7. Chiquita S, Campos EJ, Castelhano J, Ribeiro M, Sereno J, Moreira PI, Castelo-Branco M, Ambrósio AF (2019) Retinal thinning of inner sublayers is associated with cortical atrophy in a mouse model of Alzheimer's disease: a longitudinal multimodal in vivo study. Alzheimer's Res Ther 11:1-16. https://doi.org/10.1186/s13195-019-0542-8

8. Chiquita S, Rodrigues-Neves AC, Baptista FI, Carecho R, Moreira PI, Castelo-Branco M, Ambrósio AF (2019) The retina as a window or mirror of the brain changes detected in Alzheimer's disease: critical aspects to unravel. Mol Neurobiol 56:5416-5435. https://doi.org/10.1007/s1203 5-018-1461-6

9. Colom-Cadena M, Spires-Jones T, Zetterberg H, Blennow K, Caggiano A, Dekosky ST, Fillit H, Harrison JE, Schneider LS, Scheltens P, De Haan
W, Grundman M, Van Dyck CH, Izzo NJ, Catalano SM (2020) The clinical promise of biomarkers of synapse damage or loss in Alzheimer's disease. Alzheimer's Res Ther 12:1-12. https://doi.org/10.1186/s13195-020-00588 $-4$

10. Gan W-BB, Grutzendler J, Wong WT, Wong RO, Lichtman JW (2000) Multicolor "DiOlistic" labeling of the nervous system using lipophilic dye combinations. Neuron 27:219-225. https://doi.org/10.1016/S0896 $-6273(00) 00031-3$

11. Graewe B, Lemos R, Ferreira C, Santana I, Farivar R, De Weerd P, CasteloBranco M (2013) Impaired processing of 3D motion-defined faces in mild cognitive impairment and healthy aging: an fMRI study. Cereb Cortex 23:2489-2499. https://doi.org/10.1093/cercor/bhs246

12. Greenwood SM, Mizielinska SM, Frenguelli BG, Harvey J, Connolly CN (2007) Mitochondrial dysfunction and dendritic beading during neuronal toxicity. J Biol Chem 282:26235-26244. https://doi.org/10.1074/jbc.M7044 88200

13. Grimaldi A, Brighi C, Peruzzi G, Ragozzino D, Bonanni V, Limatola C, Ruocco G, Di Angelantonio S (2018) Inflammation, neurodegeneration and protein aggregation in the retina as ocular biomarkers for Alzheimer's disease in the 3xTg-AD mouse model. Cell Death Dis 9:1-10. https ://doi.org/10.1038/s41419-018-0740-5

14. Hardy JA, Higgins GA (1992) Alzheimer's disease: the amyloid cascade hypothesis. Science 256:184-185. https://doi.org/10.1126/science.15660 67

15. Hart NJ, Koronyo Y, Black KL, Koronyo-Hamaoui M (2016) Ocular indicators of Alzheimer's: exploring disease in the retina. Acta Neuropathol 132:767-787. https://doi.org/10.1007/s00401-016-1613-6

16. Ho CY, Troncoso JC, Knox D, Stark W, Eberhart CG (2014) Beta-amyloid, phospho-tau and alpha-synuclein deposits similar to those in the brain are not identified in the eyes of Alzheimer's and Parkinson's disease patients. Brain Pathol 24:25-32. https://doi.org/10.1111/bpa.12070

17. Hong S, Beja-glasser VF, Nfonoyim BM, Frouin A, Ramakrishnan S, Merry KM, Shi Q, Rosenthal A, Barres A, Lemere CA, Selkoe DJ, Stevens B (2016) Complement and microglia mediate early synapse loss in alzheimer mouse models. Science 352:712-716

18. Huang W, Fileta J, Guo Y, Grosskreutz CL (2006) Downregulation of Thy1 in retinal ganglion cells in experimental glaucoma. Curr Eye Res 31:265-271. https://doi.org/10.1080/02713680500545671

19. Hume RI, Honig MG (1986) Fluorescent carbocyanine dyes allow living neurons of identified origin to be studied in long-term cultures. J Cell Biol 103:171-187

20. Inman DM, Harun-Or-Rashid M (2017) Metabolic vulnerability in the neurodegenerative disease glaucoma. Front Neurosci 11:1-19. https:// doi.org/10.3389/fnins.2017.00146

21. Jáñez-Escalada $L$, Jáñez-García L, Salobrar-García E, Santos-Mayo A, de Hoz R, Yubero R, Gil P, Ramírez JM (2019) Spatial analysis of thickness changes in ten retinal layers of Alzheimer's disease patients based on optical coherence tomography. Sci Rep 9:1-14. https://doi.org/10.1038/ s41598-019-49353-0

22. Justino L, Kergoat MJ, Bergman H, Chertkow H, Robillard A, Kergoat H (2001) Neuroretinal function is normal in early dementia of the Alzheimer type. Neurobiol Aging 22:691-695. https://doi.org/10.1016/S0197 $-4580(01) 00234-2$

23. Koronyo-Hamaoui M, Koronyo Y, Ljubimov AV, Miller CA, Ko MK, Black KL, Schwartz M, Farkas DL (2011) Identification of amyloid plaques in retinas from Alzheimer's patients and noninvasive in vivo optical imaging of retinal plaques in a mouse model. Neuroimage 54:S204-S217. https://doi. org/10.1016/j.neuroimage.2010.06.020

24. Kotimaa J, Klar-Mohammad N, Gueler F, Schilders G, Jansen A, Rutjes H, Daha MR, van Kooten C (2016) Sex matters: systemic complement activity of female $C 57 B L / 6 \mathrm{~J}$ and BALB/CJ mice is limited by serum terminal pathway components. Mol Immunol 76:13-21. https://doi.org/10.1016/j. molimm.2016.06.004

25. Lemos R, Figueiredo P, Santana I, Simões MR, Castelo-Branco M (2012) Temporal integration of $3 \mathrm{D}$ coherent motion cues defining visual objects of unknown orientation is impaired in amnestic mild cognitive impairment and Alzheimer's disease. J Alzheimer's Dis 28:885-896. https://doi. org/10.3233/JAD-2011-110719

26. Lim JKH, Li QX, He Z, Vingrys AJ, Wong VHY, Currier N, Mullen J, Bui BV, Nguyen CTO (2016) The eye as a biomarker for Alzheimer's disease. Front Neurosci 10:1-14. https://doi.org/10.3389/fnins.2016.00536 
27. Liu YL, Hsieh YT, Chen TF, Chiou JM, Tsai MK, Chen JH, Chen YC (2019) Retinal ganglion cell-inner plexiform layer thickness is nonlinearly associated with cognitive impairment in the community-dwelling elderly. Alzheimer's Dement Diagn Assess Dis Monit 11:19-27. https://doi. org/10.1016/j.dadm.2018.10.006

28. London A, Benhar I, Schwartz M (2013) The retina as a window to the brain: from eye research to CNS disorders. Nat Rev Neurol 9:44-53. https ://doi.org/10.1038/nrneurol.2012.227

29. Mahajan D, Votruba M (2017) Can the retina be used to diagnose and plot the progression of Alzheimer's disease? Acta Ophthalmol 95:768777. https://doi.org/10.1111/aos.13472

30. Marquié M, Castilla-Martí M, Valero S, Martínez J, Sánchez D, Hernández I, Rosende-Roca M, Vargas L, Mauleón A, Rodríguez-Gómez O, Abdelnour C, Gil S, Santos-Santos MA, Alegret M, Espinosa A, Ortega G, Pérez-Cordón A, Sanabria Á, Roberto N, Moreno-Grau S, de Rojas I, Simó R, Ciudin A, Hernández C, Orellana A, Monté-Rubio G, Benaque A, Ruiz A, Tárraga L, Boada M (2019) Visual impairment in aging and cognitive decline: experience in a memory clinic. Sci Rep 9:1-10. https://doi.org/10.1038/s4159 8-019-45055-9

31. Marziani E, Pomati S, Ramolfo P, Cigada M, Giani A, Mariani C, Staurenghi $G$ (2013) Evaluation of retinal nerve fiber layer and ganglion cell layer thickness in Alzheimer's disease using spectral-domain optical coherence tomography. Investig Ophthalmol Vis Sci 54:5953-5958. https://doi. org/10.1167/iovs.13-12046

32. Mayeux R, Stern Y (2012) Epidemiology of Alzheimer disease. Cold Spring Harb Perspect Med 2:1-18. https://doi.org/10.1101/cshperspect.a006239

33. Morgan JL, Schubert T, Wong ROL (2008) Developmental patterning of glutamatergic synapses onto retinal ganglion cells. Neural Dev 3:1-19. https://doi.org/10.1186/1749-8104-3-8

34. Nunes A, Silva G, Duque C, Januário C, Santana I, Ambrósio AF, CasteloBranco M, Bernardes R (2019) Retinal texture biomarkers may help to discriminate between Alzheimer's, Parkinson's, and healthy controls. PLoS ONE 14:1-13. https://doi.org/10.1371/journal.pone.0218826

35. Poppe L, Rué L, Timmers M, Lenaerts A, Storm A, Callaerts-Vegh Z, Courtand G, de Boer A, Smolders S, Van Damme P, Van Den Bosch L, D'Hooge R, De Strooper B, Robberecht W, Lemmens R (2019) EphA4 loss improves social memory performance and alters dendritic spine morphology without changes in amyloid pathology in a mouse model of Alzheimer's disease. Alzheimers Res Ther 11:1-13. https://doi.org/10.1186/ s13195-019-0554-4

36. Prince M, Ali GC, Guerchet M, Prina AM, Albanese E, Wu YT (2016) Recent global trends in the prevalence and incidence of dementia, and survival with dementia. Alzheimer's Res Ther 8:1-13. https://doi.org/10.1186/ s13195-016-0188-8

37. Querfurth HW, Laferla FM (2010) Alzheimer's disease. N Engl J Med 362:329-344. https://doi.org/10.1056/NEJMra0909142

38. Ran C, Xu X, Raymond SB, Ferrara BJ, Neal K, Bacskai BJ, Medarova Z, Moore A (2009) Design, synthesis, and testing of difluoroboron derivatized curcumins as near infrared probes for in vivo detection of amyloid- $\beta$ deposits. J Am Chem 131:15257-15261. https://doi.org/10.1021/ja904 7043

39. Rochefort NL, Konnerth A (2012) Dendritic spines: from structure to in vivo function. Eur Mol Biol Organ 13:699-708. https://doi.org/10.1038/ embor.2012.102

40. Salobrar-García E, Rodrigues-Neves AC, Ramírez Al, de Hoz R, FernándezAlbarral JA, López-Cuenca I, Ramírez JM, Ambrósio AF, Salazar JJ (2020) Microglial activation in the retina of a triple-transgenic alzheimer's disease mouse model (3xTg-AD). Int J Mol Sci 21:1-15. https://doi. org/10.3390/ijms21030816

41. Schlamp CL, Johnson EC, Li Y, Morrison JC, Nickells RW (2001) Changes in Thy 1 gene expression associated with damaged retinal ganglion cells. Mol Vis 7:192-201

42. Serrano-Pozo A, Frosch MP, Masliah E, Hyman BT (2011) Neuropathological alterations in Alzheimer disease. Cold Spring Harb Perspect Med 1:1-23. https://doi.org/10.1101/cshperspect.a006189
43. Shi Q, Chowdhury S, Ma R, Le KX, Hong S, Caldarone BJ, Stevens B, Lemere CA (2017) Complement C3 deficiency protects against neurodegeneration in aged plaque-rich APP/PS1 mice. Sci Transl Med 9:1-14. https://doi. org/10.1126/scitranslmed.aaf6295

44. Shi Q, Colodner KJ, Matousek SB, Merry K, Hong S, Kenison JE, Frost JL, Le KX, Li S, Dodart JC, Caldarone BJ, Stevens B, Lemere CA (2015) Complement C3-deficient mice fail to display age-related hippocampal decline. J Neurosci 35:13029-13042. https://doi.org/10.1523/JNEUR OSCI.1698-15.2015

45. Shi Z, Zheng H, Hu J, Jiang L, Cao X, Chen Y, Mei X, Li C, Shen Y (2019) Retinal nerve fiber layer thinning is associated with brain atrophy: a longitudinal study in nondemented older adults. Front Aging Neurosci 11:1-10. https://doi.org/10.3389/fnagi.2019.00069

46. Spires TL, Meyer-Luehmann M, Stern EA, McLean PJ, Skoch J, Nguyen PT, Bacskai BJ, Hyman BT (2005) Dendritic spine abnormalities in amyloid precursor protein transgenic mice demonstrated by gene transfer and intravital multiphoton microscopy. J Neurosci 25:7278-7287. https://doi. org/10.1523/JNEUROSCI.1879-05.2005

47. Staffend NA, Meisel RL (2011) Diolistic labeling in fixed brain slices: phenotype, morphology, and dendritic spines. Curr Protoc Neurosci. https:// doi.org/10.1002/0471142301.ns0213s55

48. Stevens B, Allen NJ, Vazquez LE, Howell GR, Christopherson KS, Nouri N, Micheva KD, Mehalow AK, Huberman AD, Stafford B, Sher A, Litke AM, Lambris JD, Smith SJ, John SWM, Barres BA (2007) The classical complement cascade mediates CNS synapse elimination. Cell 131:1164-1178. https://doi.org/10.1016/j.cell.2007.10.036

49. De Strooper B, Karran E (2016) The cellular phase of Alzheimer's disease. Cell 164:603-615. https://doi.org/10.1016/j.cell.2015.12.056

50. Sun W, Li N, He S (2002) Large-scale morophological survey of rat retinal ganglion cells. Vis Neurosci 19:483-493. https://doi.org/10.1017/S0952 523802194107

51. Tampellini D (2015) Synaptic activity and Alzheimer's disease: a critical update. Front Neurosci 9:1-7. https://doi.org/10.3389/fnins.2015.00423

52. Williams PA, Howell GR, Barbay JM, Braine CE, Sousa GL, John SWM, Morgan JE (2013) Retinal ganglion cell dendritic atrophy in DBA/2J glaucoma. PLOS ONE 8:1-10. https://doi.org/10.1371/journal.pone.0072282

53. Williams PA, Morgan JE, Votruba M (2010) Opa1 deficiency in a mouse model of dominant optic atrophy leads to retinal ganglion cell dendropathy. Brain 133:2942-2951. https://doi.org/10.1093/brain/awq218

54. Williams PA, Thirgood RA, Oliphant H, Frizzati A, Littlewood E, Votruba M, Good MA, Williams J, Morgan JE (2013) Retinal ganglion cell dendritic degeneration in a mouse model of Alzheimer's disease. Neurobiol Aging 34:1799-1806. https://doi.org/10.1016/j.neurobiolaging.2013.01.006

55. Williams PA, Tribble JR, Pepper KW, Cross SD, Morgan BP, Morgan JE, John SWM, Howell GR (2016) Inhibition of the classical pathway of the complement cascade prevents early dendritic and synaptic degeneration in glaucoma. Mol Neurodegener 11:1-13. https://doi.org/10.1186/s1302 4-016-0091-6

56. Van Wyk M, Wässle H, Taylor WR (2009) Receptive field properties of ONand OFF-ganglion cells in the mouse retina. Vis Neurosci 26:297-308. https://doi.org/10.1017/S0952523809990137

57. Xu B, Sun A, He Y, Qian F, Xi S, Long D, Chen Y (2018) Loss of thin spines and small synapses contributes to defective hippocampal function in aged mice. Neurobiol Aging 71:91-104. https://doi.org/10.1016/j.neuro biolaging.2018.07.010

58. Zhang H, Wu L, Pchitskaya E, Zakharova O, Saito T, Saido T, Bezprozvanny I (2015) Neuronal store-operated calcium entry and mushroom spine loss in amyloid precursor protein knock-in mouse model of Alzheimer's disease. J Neurosci 35:13275-13286. https://doi.org/10.1523/JNEUR OSCl.1034-15.2015 